\title{
CES
}

COOPERATIVISMO E ECONOMÍA SOCIAL

Núm. 41 (2018-2019), páxs. 325-329

ISSN: $1130-2682$

\section{LA BAJA COMO CAUSA DE FINALIZACIÓN DE LA RELACIÓN SOCIETARIA ENTRE LA PERSONA SOCIA Y LA SOCIEDAD COOPERATIVA}

ARRIETA IDIAKEZ, F. J.

EDITORIAL DYKINSON, MADRID, 2019, 194 PÁGINAS

ISBN: 978-84-1324-347-4

PAtricia Prieto Padín*

Investigadora postdoctoral de Derecho del Trabajo y de la Seguridad Social Universidad de Deusto. 

S irva esta recensión para estimular al lector a adentrarse en la lectura de una interesante monografía que, ocupando el ordinal sexto de la específica Colección Deusto sobre cooperativismo, aborda, de forma integral, el análisis y la resolución de los interrogantes que plantea la institución de la baja del socio cooperativista.

Al margen del indudable acierto y oportunidad del objeto estudiado en un contexto de proliferación de este tipo de entidades de Economía Social y donde "no cabe desconocer que el principio de conservación del negocio jurídico, típico del Derecho del Trabajo, debe operar con más fuerza en el seno del Derecho de las cooperativas", la obra cuenta con una doble garantía de partida: de un lado, la aproximación rigurosa al tema, sustentada en un sólido y actual soporte bibliográfico a través no sólo de las fuentes legislativas (las diecisiete leyes de cooperativas vigentes en España), sino también incluyendo constantes referencias de la doctrina científica, de los laudos arbitrales del Servicio Vasco de Arbitraje Cooperativo (BITARTU), así como de las resoluciones judiciales dictadas por el Tribunal Supremo y los Tribunales Superiores de Justicia que enriquecen, más si cabe, los aspectos analizados. De otro lado, como un aval seguro, destaca el valioso aporte personal del autor proporcionado tanto por su acreditada trayectoria académica [profesor titular de Derecho del Trabajo y de la Seguridad Social de la Universidad de Deusto e investigador principal del grupo de investigación "Cooperativismo, fiscalidad, fomento, relaciones laborales y protección social" reconocido por el Gobierno Vasco], como por su significativa experiencia y buen quehacer como árbitro del BITARTU y miembro de la Junta Directiva de la Academia Vasco de Derecho.

De los cinco capítulos que componen y estructuran la monografía, el inicial contiene una breve introducción donde el autor da cuenta de la importancia del tema analizado, quedando expedito para examinar en el Capítulo Segundo, ya in extenso, y al calor del marco normativo de Derecho Cooperativo, así como de los diversos Estatutos, los distintos tipos de baja diferenciando cada figura según su naturaleza voluntaria, obligatoria o disciplinaria por expulsión. Aquellas derivadas de la libertad de trabajo o profesional, aún en la vertiente negativa, encuentran limitaciones y condicionantes diversos para el socio que el autor desgrana con tiento reflexionando sobre su acierto y legitimidad. Constatadas cuantas bajas obedecen a causas imperativas para el afectado (ya por razones que afectan a los requisitos para ostentar la condición de socio, ya por causas económicas, técnicas organizativas o de producción ligadas a la propia sociedad cooperativa, ya por fuerza mayor y otros motivos singulares y dignos de atención), remarcable es el completo compendio de soluciones abordadas con rigor que tratan de dar respuesta a la necesidad y preocupación, que debiera ser común, de ofrecer ga- 
rantías mínimas a través de un procedimiento que pase, entre muchas, desde una definición clara de las causas motivadoras, hasta la posibilidad de impugnación. En fin, aunque las bajas derivadas de una sanción disciplinaria no dejen de ser una salida obligatoria del socio por decisión del Consejo Rector, loable y requerido es el tratamiento propio y diferenciado dispuesto al lector a fin de remarcar las reglas generales y pautas específicas en función de las clases cooperativas.

Certero también el criterio seguido por el doctor Arrieta Idiakez en el Capítulo Tercero al realizar, a la luz de las fuentes legales y jurisprudenciales manejadas, una recopilación de las variopintas situaciones que dan lugar a la calificación de justificada o no justificada de cada baja voluntaria por parte del Consejo Rector de la cooperativa. Operación necesitada de deslinde por mor de la existencia de hasta veintiséis causas que no resultan extrañas o censurables (entre muchas más, la acreditación de una negación reiterada de los derechos económicos y políticos al socio; el desacuerdo de los socios con cualquier acuerdo de la Asamblea General, que implique la asunción de obligaciones o cargas gravemente onerosas no previstas en los Estatutos; la fusión de cooperativas y su proceso inverso de escisión o la alteración del objeto social de la entidad). Escenario que, con sus particularidades extensas, contrasta con las ocho causas que, hasta el momento, no se consideran de recibo (basten en este punto, la baja voluntaria sin haber desembolsado el socio el importe total de las cantidades adeudadas a la cooperativa o la realización por parte del socio de actividades competitivas).

Dispuesto el escenario anterior y siguiendo un hilo conductor admirable, las líneas del Cuarto Capítulo llevan a centrar la atención en los efectos económicos de las bajas de los socios; materia de frecuente y notable tensión entre las partes implicadas (socio cesante y sociedad cooperativa) y dispuesta a ofrecer múltiples "situaciones (...) que deben analizarse con detenimiento por ser ricas en matices". Cómo deban calcularse las obligaciones asumidas por la cooperativa con anterioridad a la baja del socio, los efectos de obligado cumplimiento que permanecen vigentes aún a pesar de la perdida de condición de socio o el singular derecho al reembolso del ex socio, forman parte del riguroso elenco de ejemplos bien conocidos por el investigador y sistematizados en dos bloques: de un lado, las reglas de juego existentes en el régimen general; de otro, aquellas otras características señeras de los regímenes particulares en función de los diferentes tipos de cooperativas, ya sean estas de trabajo, de vivienda, de explotación comunitaria de la tierra y/o del ganado, agrarias o agroalimentarias, de explotación de los recursos acuícolas, de comercio ambulante, de transportes, de servicios, de consumo o de iniciativa social.

Finaliza la monografía en el Quinto Capítulo con la valoración, de forma exhaustiva y con una perspectiva práctica, del panorama protector dispuesto a evitar la situación de necesidad en que podría quedar el socio saliente como consecuencia de la pérdida de ingresos, so pena del riesgo o exclusión social. Presenta un 
meritorio análisis del derecho a las prestaciones por desempleo o por cese de actividad de aquellos socios que causan baja en la sociedad cooperativa como contingencias del Sistema de Seguridad Social que, materializadas, su concreta manifestación y operatividad dependerá del Régimen elegido por cada cooperativa en sus Estatutos. En este contexto, especial atención merece para el autor la capitalización de tales las prestaciones como medida para ayudar a afrontar las transiciones a lo largo de la vida laboral de este colectivo, en línea con el importante enfoque del futuro del trabajo adoptado por la OIT.

Visto someramente el contenido de esta solvente y original investigación (amén de la redacción en un estilo claro, sencillo, de agradable lectura y comprensión), concurren razones de peso para afirmar que la dimensión científica, teórico y práctica, de la obra La baja como causa de finalización de la relación societaria entre la persona socia y la sociedad cooperativa hace que constituya un referente imprescindible que interese e invite a la reflexión por igual, tanto al colectivo de estudiantes y académicos, como a operadores o profesionales jurídicos. En este sentido, su especialización y perspectiva omnicomprensiva respecto a la institución de la baja de los socios cooperativistas la convierte, además, en una valiosa herramienta, incluso, punto cardinal de inspiración, para los encargados de la redacción de los Estatutos y de los Reglamentos de Régimen Interno de las cooperativas, sobre quienes pesa el deber y la labor de conocer y aplicar una normativa tan sensible como extensa y compleja.

Solo cabe felicitar muy sinceramente al autor por medio de estas modestas líneas que esperan haber servido para amplificar el conocimiento de esta obra y, sobre todo, para llamar la atención y curiosidad de quien a ellas se acerquen. 